\title{
DISCURSO DE ÓDIO E OS LIMITES JURÍDICO-CONSTITUCIONAL- DEMOCRÁTICOS DA IMUNIDADE PARLAMENTAR NA CONSTITUIÇÃO FEDERAL DE 1988
}

\author{
HATE SPEECH AND THE LEGAL-CONSTITUTIONAL-DEMOCRATIC LIMITS OF \\ PARLIAMENTARY IMMUNITY IN THE 1988 FEDERAL CONSTITUTION
}

Fabrício Veiga Costa

Alisson Alves Pinto ${ }^{2}$

\begin{abstract}
Resumo: Objetiva-se com a presente pesquisa investigar o fenômeno social do discurso de ódio presente parlamento brasileiro, delimitando-se o objeto de análise no estudo dos critérios constitucionais que regerão a aplicabilidade das premissas relacionadas à imunidade parlamentar. A escolha do tema se justifica em razão de sua relevância teórica, jurídica, social, política e econômica, especialmente no que atine à proteção e o exercício de direitos civis pertencentes às minorias sociais vulneráveis. O estudo do direito fundamental à diferença, essencial para a sociedade contemporânea marcada pelo pluralismo e pela diversidade, assim como a compreensão dos fundamentos científicos do discurso de ódio, foram de significativa importância ao estudo do tema. Por meio das pesquisas bibliográfica e documental, análises comparativas, críticas, teóricas e interpretativas, assim como a utilização do método dedutivo, foi possível demonstrar que o Supremo Tribunal Federal, nos inquéritos 3590 e 4694, manifestou-se no sentido de não punir os parlamentares acusados de discurso de ódio, sob a premissa da imunidade parlamentar. No momento em que o judiciário deixa de punir tais parlamentares, endossa o discurso social que naturaliza o ódio, a desigualdade, marginalização e segregação contra as minorias sociais vulneráveis, dogmatizando o instituto da imunidade parlamentar e permitindo que o parlamento seja um espaço de reprodução de ideais misóginos, machistas, xenófobos, homofóbicos e rascistas.
\end{abstract}

Palavras-chave. Imunidade parlamentar; Discurso de ódio; Homofobia; Racismo; Direito à diferença.

1 PÓS-DOUTORADO EM EDUCAÇÃO PELA UFMG (2015). DOUTORADO EM DIREITO PROCESSUAL PELA PUCMINAS (2012). Possui GRADUAÇÃO em Direito pela Universidade Federal de Uberlândia (2001), ESPECIALIZAÇÃO em Direito Processual pela PUCMINAS (2003); MESTRADO em DIREITO PROCESSUAL pela PONTIFÍCIA UNIVERSIDADE CATÓLICA DE MINAS GERAIS (2006); ESPECIALIZAÇÃO em Direito de Família pela PUCMINAS (2009). ESPECIALIZAÇÃO em Direito Educacional pela PUCMINAS (2014). Professor da Pós-Graduação Stricto Sensu em Proteção dos Direitos Fundamentais e da GRADUAÇÃO EM DIREITO da UNIVERSIDADE DE ITAÚNA Coordenador do Curso de Especialização em Direito Processual Constitucional da Faculdade de Pará de Minas. COORDENADOR do curso de Especialização em Direito Processual Civil na Fundação Pedro Leopoldo. Vice-coordenador do curso de Direito da Universidade de Itaúna. Professor do curso de BACHARELADO EM DIREITO na Faculdade de Pará de Minas; Faculdade Pedro Leopoldo; FAMINAS-BH e FASASETE - Faculdade Santo Agostinho de Sete Lagoas. Professor da Especialização em Direito Processual e Direito Público do IEC-PUCMINAS. Professor da PUCMINAS-VIRTUAL.E-mail:fvcufu@uol.com.br

2 Graduado em Direito pela Fundação Comunitária, Científica e Cultural de João Monlevade (2010). Pós-graduado em Direito Processual pela Pontifícia Universidade Católica de Minas Gerais (2015). Pósgraduado em Direito Empresarial pela Universidade Estácio de Sá (2016). Pós-graduado em Direito Público pela Pontifícia Universidade Católica de Minas Gerais (2017). Mestre em Direito Processual Coletivo e Efetividade dos Direitos Fundamentais pela Universidade de Itaúna (2019). Advogado criminal, família e consumerista. Professor da Faculdade CNEC Unaí. E-mail:alvespintomg@yahoo.com.br 


\begin{abstract}
The objective of this research is to investigate the social phenomenon of hate speech present in the Brazilian parliament, delimiting the object of analysis in the study of constitutional criteria that will govern the applicability of premises related to parliamentary immunity. The choice of theme is justified because of its theoretical, legal, social, political and economic relevance, especially regarding the protection and exercise of civil rights belonging to vulnerable social minorities. The study of the fundamental right to difference, essential for contemporary society marked by pluralism and diversity, as well as the understanding of the scientific foundations of hate speech, were of significant importance to the study of the theme. Through bibliographic and documentary research, comparative, critical, theoretical and interpretative analyzes, as well as the use of the deductive method, it was possible to demonstrate that the Federal Supreme Court, in inquiries 3590 and 4694, expressed itself as not punishing parliamentarians. accused of hate speech under the premise of parliamentary immunity. As the judiciary ceases to punish such parliamentarians, it endorses the social discourse that naturalizes hatred, inequality, marginalization and segregation against vulnerable social minorities, dogmatizing the institute of parliamentary immunity and allowing parliament to be a space for reproducing misogynist, sexist, xenophobic, homophobic and racists ideals.
\end{abstract}

Keywords. Parliamentary immunity; Hate speech; Homophobia; Racism; Right to the difference.

\title{
INTRODUÇÃO
}

O objetivo da presente pesquisa é investigar os limites jurídico-constitucionais e democráticos do instituto da imunidade parlamentar, visando identificar o fenômeno social do discurso de ódio presente nos discursos de alguns parlamentares, de modo a problematizar a temática no contexto da Constituição brasileira de 1988. A escolha do tema se justifica em razão de sua relevância teórica, prática e atualidade, especialmente em virtude da típica polarização de discursos antagônicos que reverberam atualmente o ódio na sociedade brasileira, na contramão dos direitos fundamentais e humanos.

Inicialmente desenvolveu-se um estudo sobre o direito à diferença e a liberdade de expressão como corolário da efetividade dos direitos humanos no Estado Democrático de Direito. A análise da manifestação de alguns parlamentares, contrária ao princípio da não-discriminação, evidencia a presença de manifestações de ódio dentro do parlamento brasileiro, fato esse que tem obstaculizado a implementação e o gozo igual dos direitos civis por todos os setores da sociedade brasileira. $\mathrm{O}$ uso indiscriminado de fundamentos morais e religiosos tem sido frequente para estigmatizar alguns grupos e setores da sociedade, como é o caso dos negros, quilombolas e homossexuais.

Como forma de ilustrar as proposições mencionadas, ressalta-se que em 3 abril de 2017, durante uma palestra no Clube Hebraica do Rio de Janeiro, o então Deputado Federal Jair Messias Bolsonaro contou que visitara um quilombo: "olha, o afrodescendente mais leve lá pesava sete arrobas. Não fazem nada! Eu acho que nem para procriador eles servem mais" (BRASIL, YouTube, 2017). No mesmo sentido, o parlamentar Marco Antônio Feliciano publicou, no dia 30 de março de 2011, na conta que mantém na rede social Twitter, manifestação de natureza discriminatória em relação a homossexuais. Eis o teor da mensagem: "a podridão dos sentimentos dos homoafetivos levam ao ódio, ao crime, a [sic.] rejeição" (FELICIANO, TWITTER; 2011). O mesmo parlamentar publicou, ainda em 31 de março de 2011, na conta do Twitter, as seguintes mensagens: 
doenças, guerras étnicas! Sobre o continente africano repousa a maldição do paganismo, ocultismo, misérias, doenças oriundas de lá: ebola, aids. Fome... etc. Sendo possivelmente o $1^{\circ}$. Ato de homossexualismo da história [sic.]. A maldição de Noé sobre canaã [sic.] toca seus descendentes diretos, os africanos. (FELICIANO, TWITTER; 2011)

A partir das manifestações supramencionadas apresenta-se o recorte proposto na presente pesquisa: quais são os limites jurídico-constitucionais e democráticos hábeis a compreender a imunidade parlamentar como um desdobramento da liberdade de expressão dos parlamentares, sem que os mesmos sejam responsabilizados por suas afirmações? A observância do princípio da não-discriminação, o princípio da dignidade humana e o direito fundamental à igualdade são alguns dos fundamentos que devem reger o instituto da imunidade parlamentar. Não é democraticamente coerente com o texto da Constituição brasileira permitir que parlamentares se utilizem indiscriminadamente de tal instituto como meio ilegítimo para a segregação, marginalidade e discriminação de pessoas. Tendo em vista a liberdade de expressão, direito constitucionalmente garantido, e a garantia da inviolabilidade, assegurada aos senadores e deputados, uma primeira impressão, descolada dos fatos acima mencionados, seria a de o discurso ser altamente protegido. Esse caso, porém, parece revelar reiterados discursos de ódio, que atentam contra a dignidade dos quilombolas e da comunidade LGBTT destinatários diretos deles.

Com a presente pesquisa será demonstrado que o uso indiscriminado da imunidade parlamentar não pode legitimar a segregação de pessoas em razão de sua raça ou orientação sexual. Verifica-se que a esses discursos é conferida uma espécie de carta branca prima facie, tendo em vista outros valores reputados relevantes. Isso porque se tende a acreditar que essa proteção leva à independência do poder legislativo e à tomada de decisões melhores no ambiente político, em especial, pelos parlamentares. É curioso observar que um traço importante da democracia é a exposição de ideias na esfera de debate público, porque isso permite que eleitores consigam eleger candidatos com os quais estejam alinhados politicamente e os eleitos, consequentemente, possam debater abertamente propostas, o que em teoria leva a decisões mais proveitosas para a sociedade.

A emissão de discursos, porém, não pode ser vista como meramente instrumental à melhor tomada de decisões, já que o aspecto deliberativo é só um dentre as possíveis funções do discurso, como a simbólica, comunicativa, persuasiva. De qualquer maneira, ela deveria aportar ônus argumentativo àqueles que emitem opiniões divergentes enquanto parlamentares, no sentido da compatibilização de visões ou convencimento. Discursos de ódio, no entanto, não parecem oportunizar isso, ao menos em regra, porque tendem à polarização de um debate e afastamento de possíveis diálogos.

No âmbito da presente pesquisa pretende-se demonstrar o que está em jogo quando se trata de discursos possivelmente cobertos pela imunidade parlamentar. Verificar-se-á se há alta ou baixa proteção desses discursos, que, por terem sido levados ao Tribunal, devem apresentar grau de ofensividade questionável, ao menos sob o aspecto subjetivo. Em suma, será posto em questão quais são as consequências do discurso de ódio na esfera parlamentar a partir da análise dos inquéritos de números 3.590 e 4.694. Isso parece ainda mais relevante se considerado o contexto de fragilidade das instituições democráticas no país e déficit de representatividade alegado por muitos cidadãos.

Nesse contexto propositivo constata-se que o estudo da liberdade de expressão dos parlamentares constitui um meio de viabilizar a participação popular e democrática, visto que é a partir 
da atividade parlamentar que a coletividade se vê representada dentro do parlamento. Por mais que cada parlamentar tenha sua "bandeira de reivindicações", que dialoga com seu eleitorado, seus discursos não podem ser construídos de modo a legitimar a ofensa aos direitos fundamentais e direitos humanos. Essa é a tônica do objeto de pesquisa proposto: problematizar os limites jurídico-constitucionais dos discursos parlamentares, para que não se sintam autorizados a utilizarem indiscriminadamente a imunidade parlamentar como um instrumento de violência contra determinados setores da sociedade, a partir da sua fala.

Não se propõe aqui a neutralidade do discurso parlamentar; o que é problematizado é o debate da responsabilização do parlamentar que reproduz livremente um discurso de ódio. Em linhas muito gerais, o discurso pode ser tecnicamente conceituado como ponto de articulação entre processos ideológicos e fenômenos linguísticos, não podendo ser encarado, então, como neutro ou natural (BRANDÃO: 2007; p. 10).

Quanto à metodologia, realizou-se a pesquisa bibliográfica e documental, mediante a consulta a fontes bibliográficas em livros e artigos científicos, além das fontes secundárias, cujos documentos contém informações hábeis a enriquecer as proposições apresentadas. O recorte da temática proposta foi possível a partir do método dedutivo, partindo-se da concepção macroanalítica, qual seja, o estudo da imunidade parlamentar, delimitando-se o estudo na investigação dos limites jurídico-constitucionais do discurso parlamentar diante das recentes manifestações de ódio reproduzidas nas falas de alguns parlamentares brasileiros. A construção das análises temáticas, teóricas, interpretativas e comparativas foi essencial para a identificação de aporias e a abordagem crítica das questões cientificamente debatidas.

\section{SOBRE O DIREITO À DIFERENÇA}

O direito fundamental à igualdade pressupõe o reconhecimento de todas as pessoas no âmbito de suas individualidades. Ao direito democrático cabe a responsabilidade de proteger todos os cidadãos indiscriminadamente, não se admitindo que a ciência jurídica seja utilizada como parâmetro para discriminar, excluir e marginalizar pessoas. Nesse cenário, o direito à diferença ressalta a necessidade de reconhecimento das diferentes identidades dos indivíduos e o alcance do direito à igualdade traz em si a premissa de não discriminação ao que é diferente.

A ética dos direitos fundamentais, que versa sobre o desenvolvimento da autonomia e respeito ao desenvolvimento das potencialidades humanas em suas mais diversas facetas, traz a concepção de que o ser humano é merecedor de igual respeito e consideração. (PIOVESAN, SILVA; 2008). A violação dos direitos fundamentais ocorre em grande medida pela dificuldade de reconhecer o outro em sua diferença e o temor ao diferente, que gera a dicotomia eu Xoutro, faz com que o distinto seja motivo para diminuir o outro em seus direitos e dignidade.

Pensar o direito à diferença no âmbito da constitucionalidade democrática exige o reconhecimento do outro como igual no que atine ao exercício dos direitos previstos no ordenamento jurídico vigente. Proteger cada sujeito no âmbito de suas individualidades, reconhecendo-o como igual, é o meio mais claro de assegurar a efetividade do direito à diferença. Thiago Penido Martins (2016), 
ao dissertar sobre a eficácia do princípio da igualdade e do postulado da proibição de discriminação nas relações jurídicas entre particulares, leciona:

\begin{abstract}
Não se olvide também das intrínsecas e umbilicais relações existentes entre o princípio da igualdade, proibição de discriminação e dignidade da pessoa humana, de modo que a análise da licitude do tratamento diferenciado deverá perpassar necessariamente pela análise se ele proporciona tratamento vexatório, humilhante ou degradante, ao ponto de configurar lesão à dignidade daquele a quem foi dispensado. (MARTINS: 2016; p. 205).
\end{abstract}

O direito à diferença é corolário do direito fundamental à igualdade. Ou seja, não é juridicamente viável sob o ponto de vista democrático utilizar-se da norma jurídica para discriminar e segregar pessoas, justificando tal tratamento a partir do cognominado direito à diferença. Pensar o direito à igualdade numa sociedade plural e marcada pela diversidade é um meio de assegurar visibilidade, dignidade e inclusão a todas as pessoas, para que não sejam discriminadas e excluídas em razão de suas escolhas realizadas no âmbito da subjetividade situada. Nessa perspectiva teórica, é importante ressaltar as fases de proteção dos direitos fundamentais: a primeira é marcada pela proteção abstrata em geral tendo como base a igualdade formal dos seres e já a segunda se refere à proteção à diversidade dos seres.

Torna-se, contudo, insuficiente tratar o indivíduo de forma genérica, geral e abstrata. Faz-se necessária a especificação do sujeito de direito, que passa a ser visto em sua peculiaridade e particularidade. Nessa ótica determinados sujeitos de direito ou determinadas violações de direitos exigem uma resposta específica e diferenciada. Vale dizer, na esfera internacional, se uma primeira vertente de instrumentos internacionais nasce com a vocação de proporcionar uma proteção geral, genérica e abstrata, refletindo o próprio temor da diferença, percebe-se, posteriormente, a necessidade de conferir a determinados grupos uma proteção especial e particularizada, em face de sua própria vulnerabilidade. Isso significa que a diferença não mais seria utilizada para a aniquilação de direitos, mas, ao revés, para sua promoção. (PIOVESAN: 2005; p. 46).

As proposições jurídicas trazidas pela modernidade baseiam-se na homogeneização de pessoas e padrões de condutas, ignorando a diversidade como característica ínsita da sociedade plural e globalizada. Aqueles sujeitos que destoam dos padrões pasteurizados e ideologizados pelas ciências são patologizados ou passam a integrar o rol das condutas consideradas criminosas pela ciência do direito. A criminalização da mendicância, a patologização da homossexualidade e da transexualidade são alguns exemplos que ilustram com clareza que as ciências médicas e jurídicas são recintos utilizados para a segregação daqueles que fogem aos padrões binários e capitalistas decorrentes de máximas generalizantes impostas institucionalmente. É nesse contexto propositivo que pessoas são segregadas, seja em razão da inadequação aos padrões homogêneos e universais, seja em virtude da naturalização da invisibilidade desses sujeitos. A igualdade formal e material proposta pelas legislações constitui um mecanismo que objetiva amenizar os impactos dessas desigualdades estruturais que acometem aqueles sujeitos naturalmente excluídos ao longo da história pelas instituições (família, sociedade, religiões, judiciário, legislativo, executivo).

A primeira fase dos direitos fundamentais se caracteriza pela ideia mais genérica de que todos os seres merecem igual proteção, evidenciando com pontualidade às máximas generalizantes impostas pela modernidade e ressaltando que a diversidade e o pluralismo social não são priorizadas como corolários do direito à diferença nesse período da história da humanidade. Esse direito 
à igualdade é consagrado no preâmbulo da Declaração Universal dos Direitos Humanos de 1948, assim como no corpo da Constituição da República Federativa do Brasil de 1988:

Considerando que, na Carta, os povos das Nações Unidas proclamam, de novo, a sua fé nos direitos fundamentais do Homem, na dignidade e no valor da pessoa humana, na igualdade de direitos dos homens e das mulheres e se declaram resolvidos a favorecer o progresso social e a instaurar melhores condições de vida dentro de uma liberdade mais ampla. (ONU, 1948).

Art. $5^{\circ}$ Todos são iguais perante a lei, sem distinção de qualquer natureza, garantindo-se aos brasileiros e aos estrangeiros residentes no País a inviolabilidade do direito à vida, à liberdade, à igualdade, à segurança e à propriedade, nos termos seguintes [...]. (BRASIL; 1988).

Verificada a particularidade de cada ser humano, a segunda fase já coloca o direito à diferença como fundamental, de modo que a proteção ao diverso é ressaltada. Ademais, ao assumir o direito à igualdade como imanente a todos os cidadãos, o direito à diferença acaba sendo um fator de enriquecimento dessa igualdade. $\mathrm{O}$ reconhecimento do direito à diferença veio a partir do princípio da não-discriminação, expressamente previsto no artigo 3, inciso IV da Constituição brasileira de 1988, que é clara ao estabelecer que constitui objetivo fundamental da República Federativa do Brasil a promoção do bem de todos, sem qualquer manifestação de preconceito decorrente da origem, raça, sexo, cor, idade e quaisquer outras formas de discriminação. Diferente da primeira fase, a segunda já reconhece a diversidade de cada ser humano e busca colocar todos os indivíduos na mesma posição (com os mesmos direitos e liberdades), de modo que a dicotomia eu x outro não enalteça e tampouco subjugue ninguém (PIOVESAN, SILVA; 2008). Nesse sentido:

Enquanto a igualdade pressupõe formas de inclusão social, a discriminação implica violenta exclusão e intolerância à diferença e diversidade. Assim, a proibição da exclusão, em si mesma, não resulta automaticamente na inclusão. Logo, não é suficiente proibir a exclusão, quando o que se pretende é garantir a igualdade de fato, com a efetiva inclusão social de grupos que sofreram e sofrem um consistente padrão de violência e discriminação. (PIOVESAN, SILVA: 2008; p. 12).

O reconhecimento do direito à diferença passa pela proibição de exclusão de pessoas a partir da lei. Importante ressaltar que no momento que a legislação proíbe a exclusão não assegura automaticamente a inclusão, ou seja, a superação da exclusão, marginalidade e segregação a partir da lei decorrerá não apenas da proibição legal, haja vista que o mais relevante é a efetividade normativa que deve assegurar materialmente a correção da desigualdade estrutural naturalizada pelas instituições. $\mathrm{O}$ pensamento de Boaventura de Souza Santos vai ao encontro dos objetivos da segunda fase:

[...] temos o direito a ser iguais quando a nossa diferença nos inferioriza; e temos o direito a ser diferentes quando a nossa igualdade nos descaracteriza. Daí a necessidade de uma igualdade que reconheça as diferenças e de uma diferença que não produza, alimente ou reproduza as desigualdades. (SANTOS, NUNES: 2003; p. 56).

Pensar o direito à diferença na perspectiva democrático-constitucionalizada, e no contexto dos direitos humanos, é pretender se utilizar das proposições legislativas como meio hábil a desconstrução de uma desigualdade estrutural naturalizada historicamente na sociedade brasileira. Nesse ínterim, a visibilidade das diferenças é o que leva a busca por uma sociedade igualitária, ou 
seja, com o reconhecimento da diferença entre as pessoas é possível buscar um tratamento igualitário a todas. Ao contrário, a tentativa de tratar da maneira igual aqueles que são diferentes contribui para o aumento da discriminação.

[...] Assim sendo, se torna legítimo pensar no reconhecimento da diferença e da peculiaridade de uma minoria (negros, mulheres, deficientes, sem-terra...), mais do que na pressuposição da igualdade genérica de todos (povo, cidadão). É recente, portanto, a percepção de que a noção de igualdade faz sombra à possibilidade de um reconhecimento da singularidade ou particularidade de cada qual. (BITTAR: 2009; p. 552).

No Brasil, a diferença tem sido fator de grande desigualdade social, pois, diante da realidade política, econômica e social, o diferente é motivo de discriminação. É justamente essa desigualdade estrutural, decorrente de fatores sociais, econômicos, históricos, morais e religiosos, que justifica a intervenção da ciência do direito em propor meios, através da lei, de promover a ressignificação desse modelo que institucionalizou desigualdades estruturais, visando segregar determinados setores da sociedade que não aderiram aos padrões homogeneizantes de condutas e forma de vida. Nesse contexto propositivo, ressalta-se:

O Brasil possui uma identidade cultural híbrida ante a pluralidade. Historicamente, a diferença no país tem sido motor da desigualdade social. As dinâmicas culturais estão entrecruzadas com as realidades políticas, econômicas e sociais. O imaginário incrustado na diferença resulta numa sociedade desigual e injusta. Isso porque a diferença passou a significar desigualdade, exclusão (CANCLINI, 2001; CARDOSO: 2003; p, 91).

A partir do entendimento de que um tratamento homogeneizante com pessoas desiguais é insuficiente para atender os anseios sociais, o tratamento jurídico do direito à diferença no Brasil tem se modificado. Novamente é importante esclarecer que o reconhecimento do direito à diferença não se restringe à proibição legal da discriminação e desigualdade. Desconstruir as desigualdades estruturais sedimentadas historicamente pelas instituições exige o desafio de alcançar a efetividade e aplicabilidade materiais das proposições legais que reconhecem o tratamento igualitário dos sujeitos que fogem aos padrões binários, capitalistas, sociais, morais e religiosos, esclarecendo-se que a proteção da igualdade, no contexto do direito à diferença, tem como pressuposto a visibilidade do pluralismo e da diversidade que caracterizam a sociedade contemporânea.

Em razão do contexto mundial e do cenário do holocausto, a aplicação do direito em sua característica puramente liberal, assim como puramente positivista, foi abandonado e, com a terceira geração dos direitos fundamentais, a ideia de universalidade, fraternidade e solidariedade passaram a aumentar as garantias voltadas para o direito às diferenças, como a autodeterminação dos povos, entre outros.

A partir da terceira geração dos direitos fundamentais, concebida diante da comoção mundial com os horrores do holocausto, notabilizou-se a decadência tanto da aplicação puramente liberal do direito quanto do positivismo jurídico, uma vez que o problema da justiça foi praticamente abandonado em prol de um normativismo que fechava os olhos à realidade social. A referida geração consagrou os chamados direitos de fraternidade, que possibilitavam que ideias como a solidariedade e universalidade passassem a permear a discussão jurídica, dando azo ao surgimento de garantias como a autodeterminação dos povos, o meio ambiente equilibrado e a preocupação com as gerações futuras. (FARIAS: 2015; p. 24). 
A terceira geração dos direitos fundamentais evidencia a superação dos ideários individualistas que permeavam o debate dos direitos fundamentais, notabilizando-se por proposições que enaltecem a proteção dos direitos metaindividuais, além de um olhar mais específico para a diversidade, pluralismo e direito à diferença. Nesse sentido, a Constituição da República Federativa do Brasil de 1988 traz a ideia de pluralismo e incentiva a participação dos mais diversos grupos na política nacional, e diante desse cenário, nota-se que a ideia de um Estado Democrático de Direito, proclamado pela Constituição de 1988 (BRASIL; 1988), apresenta destaque especial ao princípio da dignidade humana, corolário dos direitos à igualdade e à diferença. Nesse contexto propositivo, verifica-se:

\footnotetext{
Ressalte-se, ainda, o total destaque dado ao (super)princípio da dignidade da pessoa humana, que emerge como maior fundamento do Estado Democrático de Direito, ocupando o lugar de destaque antes dado ao princípio da legalidade. Tal tendência não é um fenômeno isolado, tendo sido verificado de forma geral ao redor do mundo, como parte da renovação constitucional impulsionada pelo pós-guerra e pelas discussões em torno da terceira geração dos direitos fundamentais. (FARIAS: 2015; p. 26).
}

A dignidade humana emerge como fundamento da República Federativa do Brasil, expressamente mencionada no artigo 1 da Constituição brasileira de 1988, para despatrimonializar a forma de compreender a ciência do direito, colocando a pessoa humana como centro da proteção jurídica de todo o ordenamento legal. Nesse contexto, a ampla proteção integral da pessoa humana exige o respeito à diferença, o reconhecimento do outro como igual no que tange ao acesso aos direitos civis, além da vedação de qualquer tipo de discriminação ou preconceito que venham a reproduzir o modelo institucionalizado de segregação daquelas pessoas que fogem aos padrões homogêneos impostos pelos ideais individualistas e patrimonialistas reproduzidos pela modernidade.

Assim, com a exaltação da dignidade humana, o direito à diferença encontra-se amparado pela perspectiva universalista que considera o ser humano como destinatário final da tutela jurídica, de modo que o respeito a sua individualidade e realização é observado. "Nesse contexto, ocorre à afirmação da urgência de reconhecimento das necessidades não apenas da ampla coletividade, mas dos grupos minoritários que compõem o tecido social, dando-lhes proteção e visibilidade" (FARIAS: 2015; p. 26). O direito à diferença se traduz em uma luta pelo reconhecimento das classes minoritárias da sociedade, que dentro da dicotomia eu x outros constantemente é prejudicada. "Percebe-se que o mero decreto de igualdade de todos perante a lei não salvaguarda a possibilidade de realização do reconhecimento pleno, na vida social” (BITTAR: 2009; p. 553). Nota-se, então, que o equilíbrio das relações humanas não é suprido pela ideia de igualdade, mas sim pelo reconhecimento da diversidade da natureza humana, como forma de desconstrução das estruturas de dominação (família, Estado, sociedade, igreja) que naturalizam historicamente a marginalidade, exclusão, segregação e desigualdade daqueles sujeitos que integram as "ditas" minorias sociais. Por isso, é importante esclarecer:

O direito à diferença está baseado na ideia de que todos são diferentes entre si; e, propriamente, isto é ser humano, em sua singularidade. Para conceituar a 'natureza humana', deve-se, portanto, respeitar as singularidades. Isso faz com que seja necessário assumir a complexidade da diversidade (BITTAR: 2009; p. 555). 
Esse reconhecimento da diversidade humana, por ser uma manifestação latente da proteção aos direitos fundamentais, acaba se tornando um dos valores constitutivos da ideia de justiça dentro da sociedade, juntamente à igualdade. Ou seja, o que é único não pode ser comparado nem classificado, tampouco visto como igual ou desigual (HELLER; 1998). E junto à ideia de justiça social, a sociedade contemporânea, em razão de sua pluralidade, tem como forte característica a luta pelo reconhecimento e igual tratamento de todos os cidadãos na medida de suas diferenças. Para Habermas, "as condições concretas de reconhecimento, seladas por uma ordem jurídica legítima, resultam sempre de uma luta por reconhecimento" (HABERMAS: 2003; p. 168-9).

Na visão de Farias (2015), a tutela do direito à diferença ocorre em três eixos: repressivo, inclusivo e preventivo. Repressivo na medida em que as normas punitivas servem para tutelar as identidades individuais e grupais, servindo o direito penal como instrumento para promover a cidadania. Como exemplo de atuação desse eixo menciona-se a Lei 7.716/1989 (BRASIL; 1989), que trata dos crimes resultantes de preconceito por raça, cor, etnia, credo ou nacionalidade (FARIAS; 2015). Preventivo, com a utilização de políticas públicas, tal como a educação, voltadas para a defesa dos direitos humanos, partindo do pressuposto de que o auxílio no reconhecimento do que é dignidade assim como no exercício da cidadania, são capazes de promover a dignidade dos indivíduos (FARIAS; 2015). O eixo inclusivo, por sua vez, consiste em ações do poder público ou privado que, por meio de ações afirmativas, buscam orientar os cidadãos quanto à solução das situações de desigualdade já existentes, visando assim ao desfazimento de exclusões históricas. Ações desse eixo encontram-se, por exemplo, nas políticas públicas voltadas ao público LGBTQI, assim como as minorias historicamente marginalizadas, bem como as cotas raciais para ingresso na educação de nível superior e concursos públicos (FARIAS; 2015).

A partir das premissas apresentadas, nota-se que o direito à diferença está necessariamente atrelado à liberdade individual e a dignidade humana, de tal modo que cada ser humano seja capaz de se autodeterminar em suas mais diferentes singularidades. Nesse sentido, a liberdade individual se manifesta como um direito capaz de contribuir para a 'luta do reconhecimento' na sociedade contemporânea, restando saber os limites de sua manifestação por cada indivíduo para evitar que esse direito, ao invés de dar voz às minorias, as oprima com mais veemência. A dignidade humana, vista como corolário do direito à diferença, é considerada o fundamento regente da autodeterminação das pessoas em escolherem a forma como pretendem construir sua vida sem as amarras e intervenções ilegítimas de instituições que objetivam, muitas vezes, manter o status da naturalizada desigualdade estrutural e a marginalidade que acometem os grupos minoritários.

\section{DEMOCRACIA QUE PREZA POR DIREITOS HUMANOS, DISCURSO DE ÓDIO E LIBERDADE DE EXPRESSÃO}

A proteção dos direitos humanos, a repressão do discurso de ódio contra as minorias, a regulamentação dos limites constitucionais do exercício do direito fundamental de liberdade de expressão, a efetividade do princípio da não-discriminação e o repúdio a qualquer meio ou forma de tornar invisível o direito à diferença são alguns compromissos assumidos pelo Estado Democrático de Direito. Não se propõe aqui a fazer uma reflexão teórica profunda, de modo a limitar os con- 
ceitos definitivamente, mas é necessário ao menos problematizar algumas questões essenciais ao debate crítico do objeto da presente pesquisa. Uma primeira aproximação possível com os temas de discursos violentos, liberdade de expressão e democracia que preza por direitos humanos parte da noção de que as identidades humanas são necessariamente formuladas na interlocução com o outro. O diálogo com o outro, no sentido mais amplo possível, é o que viabiliza a consolidação do próprio “eu”, tanto na afirmação e retroalimentação do que os outros afirmam, quanto na luta contra o que querem ver em nós.

A partir das proposições trazidas por Robert Alexy, "parece plausível supor que a liberdade é uma qualidade, uma qualidade que, por exemplo, pode ser atribuída a pessoas, ações e sociedades" (ALEXY: 2003; p. 219). Ou seja, "essa seria, no entanto, uma perspectiva bastante rudimentar e superficial. Quem diz que uma pessoa é livre pressupõe que, para que essa pessoa não existem embaraços, restrições ou resistências de qualquer espécie” (ALEXY: 2003; p. 219). “Com isso, poder-se-ia considerar liberdade com uma relação diádica entre uma pessoa e um embaraço à liberdade. Mas isso não é suficiente" (ALEXY: 2003; p. 219).

Na perspectiva acima apresentada fica evidente que o direito fundamental à liberdade não é absoluto, visto que deve ser exercido de modo a tornar viável a proteção integral da dignidade humana das minorias, requisito essencial para a implementação das premissas democráticas trazidas pelo texto constitucional vigente. A existência de conflitos entre direitos fundamentais no plano da aplicação exige a ponderação das normas diante do caso concreto, privilegiando o exercício das liberdades individuais e coletivas no contexto propositivo da dignidade humana daqueles sujeitos vulneráveis, excluídos, marginalizados e que integram o grupo das minorias.

O discurso democrático deve tornar visível os direitos de todos os segmentos da sociedade civil, exigindo-se a proteção jurídico-constitucional da diversidade e do pluralismo social. Sendo um processo que se mantém durante toda a vida, a identidade humana, portanto, é socialmente construída. Nesse sentido, ela é dependente de um diálogo e, por isso, pode ser muito afetada a depender dos imputs realizados pelas outras pessoas. Para integrantes dos grupos minoritário o processo de descoberta e reconhecimento de identidades pode ser violento. Isso porque, ao serem alvo de interlocuções que, de alguma forma, colocam-lhes em patamar de cidadania inferior ao que lhes é juridicamente garantido, eles acabam sendo atingidos ao menos de duas formas diferentes. A primeira delas é no diálogo interior com eles mesmos, podendo se converter em enfraquecimento da autoestima e depreciação. Como afirma Taylor, "o reconhecimento errôneo [...] [pode] ainda infligir um terrível ferida, aprisionando suas vítimas num paralisador ódio por si mesmas" (2013, p. 242). A segunda, por sua vez, é no nível público, no espaço social, derivando do efeito que discursos inferiorizantes proferidos por algumas instituições podem causar em outras pessoas. Esses discursos apresentam o potencial de incentivar outros membros da sociedade a também inferiorizar minorias e eventualmente também lhes agredir fisicamente ou de outras formas (TAYLOR: 2013; p. 242).

Isso posto, é de se entender o porquê de alguns discursos serem considerados odiosos. São odiosos aqueles discursos que inferiorizam ou depreciam alguma pessoa ou grupo social, tendo em vista que causam danos físicos e/ou psicológicos aos seus destinatários. Ao bloquearem a via do reconhecimento das identidades, que é "uma necessidade humana vital" (TAYLOR: 2013; p. 
242), eles subjugam à marginalização social os cidadãos que as pleiteiam, em alguma medida, restringindo, no limite, sua própria liberdade de expressão. O Brasil, por exemplo, apresenta dados alarmantes sobre violência contra minorias, notadamente mulheres, negros e LGBTQIs. Só no ano passado, por exemplo, foi registrada uma morte de mulher a cada duas horas, quase seis estupros por hora e uma morte de LGBT a cada 26 horas. Além disso, em 2015, os números indicaram que, do total de homicídios, 71\% foram cometidos contra negros (BRASIL, O Globo, 2018).

Liberdade de expressão, nesse contexto, não pode ser enxergada como o direito de ilimitadamente se utilizar de linguagens para veicular posições. Em um regime político democrático, que ao menos se propõe a prezar pelo igual respeito e dignidade entre seus cidadãos, isto é, por direitos humanos grosso modo, não é possível considerar que todo cidadão - incluindo-se aqui a classe política - possa vociferar palavras de ódio a outros, estando isso dentro de sua esfera de direitos.

A liberdade de expressão encontra limites em outros valores reputados importantes e, no limite, na própria segurança dos membros da comunidade política. O preconceito e o ódio, portanto, não podem ser considerados exercícios da liberdade individual, sob pena de serem vistos sob uma ótica individualizante e de cortesia, quando, na verdade, estão em jogo problemas estruturais e de justiça social. Pensar a liberdade de expressão numa sociedade democrática implica em privilegiar a observância dos direitos fundamentais, ou seja, todas as vezes que o referido direito for absolutizado, permitindo-se que pessoas sejam ilimitadamente livres para expressar o que quiserem, abre-se a possibilidade de institucionalizar o discurso de ódio, cuja sistematização é reflexo da contrariedade da teoria dos direitos fundamentais.

\section{DISCURSOS DE ÓDIO NO PARLAMENTO}

A dogmatização na forma de compreender a imunidade parlamentar tem causado reflexos diretos na violência que atinge os grupos minoritários. Alguns parlamentares no Brasil têm se utilizado dessa máxima para expor seus discursos odiosos contra minorias, sustentando que estão amparados pelo exercício do direito de liberdade de expressão. Essas condutas evidenciam a forma distorcida de compreender a liberdade de expressão e imunidade parlamentar, já que tais temas não podem ser desconectados da observância dos direitos fundamentais, direitos humanos, dignidade humana e vedação de preconceito. Nesse sentido, o exercício livre de qualquer direito numa sociedade democrática pressupõe o dever de seu titular não segregar seus interlocutores quanto o exercício dos direitos civis previstos no plano legislativo.

A partir dessas proposições iniciais é importante destacar que o Ministério Público Federal promoveu denúncia contra o pastor e parlamentar Marco Feliciano: “acordam os Ministros da Primeira Turma do Supremo Tribunal Federal em não receber a denúncia no inquérito, nos termos do voto do relator e por unanimidade, em sessão presidida pelo Ministro Marco Aurélio, na conformidade da ata do julgamento e das respectivas notas taquigráficas" (BRASIL, INQUÉRITO 3.590, 2014), por declarações que indicam preconceito e discriminação, além de incitar o ódio entre grupos (são manifestações especialmente direcionadas para a comunidade LGBT). A principal declaração vinculada ao pastor evangélico foi inserida como mensagem em sua conta na rede social 
Twitter, com o seguinte conteúdo: "a podridão dos sentimentos dos homoafetivos levam [sic.] ao ódio, ao crime, a [sic.] rejeição" (TWITTER, 211).

A partir da exposição acima realizada verifica-se que o STF considerou o fato atípico; entretanto, mostrou que o ordenamento repudia a fala do parlamentar, indicando o caminho da confecção de legislação específica para tipificar tais condutas. Mais que isso: identificou a presença do fenômeno discurso de ódio (ou manifestações de ódio), denominado no voto do Ministro Luís Roberto Barroso como hate speech, conforme consta abaixo:

Eu até consideraria razoável que o Princípio da Dignidade da Pessoa Humana impusesse um mandamento ao legislador para que tipificasse condutas que envolvam manifestações de ódio, de hate speech [sic.], como observou a Doutora Deborah Duprat. Mas a verdade é que essa lei não existe. Existe até um projeto de lei em discussão no Congresso Nacional. De modo que eu acho que vulneraria princípios que nós consideramos importantes se a própria jurisprudência do Supremo Tribunal Federal punisse criminalmente alguém sem que uma lei claramente defina essa conduta como ilícita. De modo que, por mais reprovável que se considere essa manifestação no plano moral, eu penso que não é possível tipificá-la penalmente, de modo que estou acompanhando Vossa Excelência pelo não recebimento da denúncia. (BRASIL, 2014)

É relevante esclarecer que mesmo restando comprovado no Inquérito 3.590, de 2012, a existência do discurso de ódio de parlamentar contra minorias sexuais, o posicionamento do Supremo Tribunal Federal foi no sentido de não receber a referida denúncia por considerar a conduta praticada como atípica. Mais uma vez a ciência do Direito é utilizada dogmaticamente para ratificar as estruturas sociais que naturalizam do preconceito, segregação, marginalidade e discriminação contra a comunidade LGBTQI. No momento em que o Poder Judiciário deixa de reconhecer a ilicitude de tal conduta, ratifica sua legitimidade, mesmo estando evidente a ofensa ao direito fundamental à igualdade, dignidade humana, vedação de discriminação, exercício abusivo e autocrático da liberdade de expressão parlamentar. Fundado na tese da atipicidade penal o Poder Judiciário brasileiro endossa o discurso de ódio contra as minorias sexuais, robustecendo a institucionalização do preconceito e a discriminação.

A mensagem do parlamentar pode ser examinada do ponto de vista da possibilidade de identificação do fenômeno, das proibições de preconceito e discriminação impostas pela própria Constituição Federal, no seu artigo 3. ${ }^{\circ}$, inciso IV, que estabelece a promoção do bem de todos, sem preconceitos de origem, raça, sexo, cor, idade e quaisquer outras formas de discriminação. Realizando-se o teste de substituição por alguns critérios ali expostos, podemos perceber bem a discriminação. Vejamos:

A podridão dos sentimentos dos negros levam [sic.] ao ódio, ao crime, a [sic.] rejeição. A podridão dos sentimentos dos judeus levam [sic.] ao ódio, ao crime, a [sic.] rejeição. A podridão dos sentimentos das mulheres levam [sic.] ao ódio, ao crime, a [sic.] rejeição. (BRASIL, 2014).

Note-se que a substituição dos critérios de proibição mantém as características identificadoras do fenômeno, pois são manifestações de caráter discriminatório, intolerantes ao diferente, que induzem ao ódio a um determinado grupo. A inferiorização provocada pela fala coloca o grupo na condição de inimigo e, mais que isso, resulta em fato criminoso, como se o fato de pertencer a tal grupo conduzisse naturalmente ao crime. A mensagem, mesmo que substituídos os critérios 
de proibição, continua a indicar uma situação caótica, motivada por ideologias racistas, sexistas, antissemitas ou homofóbicas.

Há uma nota de repúdio ao diferente, por exemplo, no que se refere ao comportamento orientação - sexual do indivíduo. O sujeito diferente, que escape da visão conservadora a qual preconiza a matriz sexual binária (homem e mulher), é considerado inimigo e, ao mesmo tempo, protagonista da catástrofe social. O diferente poderá provar a extinção tanto da família quanto da própria humanidade, sendo essa é a perspectiva do acionamento do pânico moral. As hipóteses formuladas funcionam de acordo com a possibilidade de atribuição de estereótipos aos grupos conforme os papéis que devam cumprir ou os papéis que lhes são atribuídos. Em relação à hipótese das mulheres, melhor seria, sob esse ângulo, reformulá-la da seguinte forma: "a podridão dos sentimentos das mulheres feministas levam [sic.] ao ódio, ao crime, a [sic.] rejeição" (BRASIL, 2014). Miskolci apresenta uma perspectiva interessante sobre o pânico moral:

\begin{abstract}
Analiso a polêmica por meio do mecanismo de resistência e controle da transformação societária conhecido como pânicos morais, aqueles que emergem a partir do medo social com relação às mudanças, especialmente as percebidas como repentinas e talvez por isso mesmo, ameaçadoras. No caso do casamento gay é necessário reconstituir historicamente o temor com relação a gays e lésbicas que marca a rejeição deste direito que há algumas décadas pareceria um puro e simples paradoxo já que a identidade gay e o casamento eram vistos como opostos (MISKOLCI: 2007; p. 103).
\end{abstract}

Essa expressão aparece em outras falas, como no projeto de "cura gay" - de decreto legislativo, apresentado pelo deputado João Campos para sustar a aplicação do parágrafo único do art. $3^{\circ}$, bem como a do art. $4^{\circ}$, da Resolução do Conselho Federal de Psicologia no 1/99, de 23 de março de 1999, que estabelece normas de atuação para os psicólogos em relação à questão da orientação sexual, em que se manifesta o repúdio ao diferente, a ponto de promover a "cura" dos homossexuais. Esta ilustra com perfeição essa atitude mental, esse pensamento que busca o banimento do diferente ou da sua condição diferenciadora de grupo.

A naturalização do discurso de ódio pelas instituições, visto como algo normal, desiguala estruturalmente as pessoas segregadas, pois as mesmas não são vistas como sujeitos legitimados a exercer e gozar de todos os direitos previstos no plano legislativo, pelo simples fato de suas escolhas não condizerem com a homogeneização de condutas sedimentadas socialmente. A reprodução desse discurso torna tão natural o ato de excluir e segregar pessoas que as próprias instituições ficam paralisadas diante dos pedidos e manifestações contrárias a esses discursos de ódio que ecoam com frequência e naturalidade por muitos de seus interlocutores. Aqueles cidadãos que se identificam com o discurso de ódio são os mesmos que fomentam sua reprodução, identificando-se com as falas dos parlamentares que abusam do exercício da imunidade parlamentar.

Outro exemplo que vem ilustrar com clareza a problemática científica exposta diz respeito ao ex-deputado Jair Bolsonaro (PSL-RJ), atual presidente do país, que em 03 de abril de 2017, durante uma palestra no Clube Hebraica do Rio de Janeiro, contou que visitara um quilombo e que sua conclusão foi a seguinte: "olha, o afrodescendente mais leve lá pesava sete arrobas. Não fazem nada! Eu acho que nem para procriador eles servem mais" (BRASIL, YouTube, 2017). Ressalta-se que mais uma vez o Supremo Tribunal Federal (STF) rejeitou a denúncia de racismo apresentada contra o referido (então) parlamentar em abril de 2018, pela procuradora-geral da República, Raquel 
Dodge. O posicionamento do Supremo Tribunal Federal foi reconhecer que as declarações são totalmente desconectadas da realidade, mas, no caso em questão, apesar da grosseria, da vulgaridade, não parece ter extrapolado limites da sua liberdade de expressão qualificada, disse o ministro Alexandre de Moraes, que tinha adiado seu voto duas vezes, ao formar a maioria de 3 a 2 contra a denúncia na Primeira Turma do STF. O relator do processo, Marco Aurélio Mello, e o ministro Luiz Fux já tinham votado para rejeitar a denúncia, pois interpretaram que as falas de Bolsonaro questionadas pela Procuradoria Geral da República (PGR) se inserem no contexto da liberdade de expressão.

Novamente o Supremo Tribunal Federal endossa como lícito o discurso de ódio racial perpetrado por parlamentar, tornando explícito que o Poder Judiciário contribui de forma direta com a estrutura social que reproduz o discurso de ódio como algo natural. Os ministros justificaram suas posições a partir de argumentos ideológicos e dogmáticos, uma vez que consideram a liberdade de expressão parlamentar quase que algo sagrado, que não merece qualquer intervenção, mesmo que tais manifestações destoem da teoria dos direitos fundamentais, violem direitos humanos, atentem contra a dignidade humana e constituem explícita ofensa ao princípio da não-discriminação. O mais importante para o Poder Judiciário é manter a dogmática concepção da imunidade parlamentar, mesmo que o parlamento seja um locus que reverbere ódio e segregação contra grupos minoritários.

A denúncia foi oferecida ao STF por Raquel Dodge no dia 13 de abril. Ela se baseou em palestra proferida por Bolsonaro no ano de 2017 no Clube Hebraica, no Rio de Janeiro. A procuradora acusou o deputado de racismo e manifestações discriminatórias contra quilombolas, índios, refugiados, mulheres e lésbicas, gays, bissexuais, travestis e transexuais. Votaram pela aceitação da denúncia os ministros Luís Roberto Barroso e Rosa Weber. Para eles, Bolsonaro deveria se tornar réu e responder à ação penal pelos crimes de discriminação e incitação ao crime por declarações em relação aos gays e aos quilombolas. A ministra Rosa Weber levou em conta apenas o caso dos quilombolas, segundo esclareceu. Apesar de ter escapado de um novo processo, Bolsonaro responde a outras duas ações penais no STF, nas quais é acusado de injúria e de incitação ao estupro devido a declarações feitas sobre a deputada Maria do Rosário (PT-RS). Importante consignar que as referidas ações se encontram suspensas pelo ministro Luiz Fux, do STF, e na decisão em que também suspendeu os prazos prescricionais, o ministro justificou sua decisão citando dispositivo da CF que prevê que o presidente, na vigência do mandato, não pode ser responsabilizado por atos estranhos ao exercício de suas funções.

Em seu voto, o ministro Alexandre de Moraes destacou que as declarações de Bolsonaro são absolutamente desconectadas da realidade. Suas declarações, principalmente as mais grosseiras e vulgares em momento algum tiveram intuito, pelo menos o intuito objetivo que se percebe, de negar o sofrimento ou ser contra o sofrimento causado aos negros e seus descendentes pela escravidão, completou o ministro. Segundo ele, o cerne da manifestação [de Bolsonaro] é uma crítica a políticas de governo, a políticas com as quais não concorda o denunciado, não chegando a extrapolar para um discurso de ódio. Novamente verifica-se na manifestação do ministro Alexandre de Moraes forte carga axiológica, evidente protagonismo judicial utilizado como meio de, talvez, querer justificar a fala do parlamentar, para, assim, afastar sua responsabilidade jurídica. A partir dessa postura o judiciário mais uma vez endossa o discurso de ódio contra minorias sociais ao não 
aplicar qualquer responsabilidade jurídica àqueles que incitam o ódio, exclusão, marginalidade e segregação.

O discurso de ódio, nas perspectivas acima mencionadas, aciona o pânico moral, pelo medo coletivo de uma mudança social que prejudique o grupo que se está representando, como esclarece Miskolci (2007), e dominante em relação àquilo que se quer manter. Ao mesmo tempo, deve identificar um inimigo e estimular contra este a intolerância e, consequentemente, o ódio. Tal fenômeno mostra um sujeito ativo indefinido, podendo ser tanto um indivíduo político com status e proteção parlamentar, quanto um grupo de políticos com a mesma identidade ideológica e proteção parlamentar. Como sujeito passivo, pode-se observar uma coletividade identificável como grupo não dominante, que compartilha elementos culturais, religiosos, sociais, geralmente em estado de vulnerabilidade.

\section{PANORAMA DAS CONSEQUÊNCIAS DO DISCURSO DE ÓDIO NA ESFE- RA PARLAMENTAR}

A análise dos reflexos e consequências decorrentes do discurso de ódio na esfera parlamentar é uma questão que ultrapassa em muito os estudos e as proposições jurídicas. Toda fala de um parlamentar pode ser vista como um meio de endossar ou revisitar estruturas de violência e dominação. Quando um parlamentar reproduz discursos de ódio contra minorias sociais simplesmente reforça a institucionalização do preconceito e discriminação já naturalizados na sociedade brasileira. Além disso, torna-se relevante problematizar brevemente o debate acerca da responsabilidade penal do parlamentar que reproduz discursos de ódio contra minorias, pretendendo-se ser blindado na máxima trazida pela imunidade parlamentar. Embora esse não seja especificamente o objeto do presente artigo científico, é relevante esclarecer que a intervenção do direito penal será a ultima ratio jurídica utilizada para prevenir ou reprimir condutas, falas e atitudes voltadas a manutenção das estruturas de dominação que privilegiam a exclusão de grupos minoritários.

Pensar o discurso de ódio nas manifestações do parlamentar permite, num primeiro momento, que ele seja identificado, demarcando-se a expressão como fora do campo democrático. Isso possibilita marcar, isolar e combater essas falas dentro do contexto da dinâmica parlamentar. Por isso, adquire relevância no contexto político-jurídico compreender que certos discursos transgridem as fronteiras daquilo que pode ser aceito em uma democracia ancorada em direitos humanos. Num segundo momento, pode-se questionar se há consequências sancionatórias quando o discurso do ódio é perpetrado pelo parlamentar ou na esfera da manifestação parlamentar. Quando se fala no discurso de ódio, no caso brasileiro, além da tensão natural existente com a liberdade de expressão, os parlamentares encontram na imunidade proteção em relação à rede sancionatória do sistema jurídico brasileiro (CONSTITUIÇÃO FEDERAL BRASILEIRA, 1988), pois os parlamentares são invioláveis, civil e penalmente, por quaisquer de suas opiniões, palavras e votos.

A proteção ampla da palavra aos parlamentares, etimologicamente mais que adequada, uma vez que parlamento é exatamente o poder que fala (KURAKANA: 2002; p. 85), ganha contornos de indispensabilidade em tempos de consolidação da democracia. Os representantes do povo necessitam desse poder de fala maximizado em seus debates políticos, sempre realizados em função 
do desempenho do mandato (prática in officio) ou em razão dele (prática propter officium). A proteção aos parlamentares no que tange a sua liberdade de expressão leva a uma defesa da possibilidade de que a imunidade seja interpretada não como regra, mas como princípio, no sentido de colocar como limite intangível o discurso do ódio e enfrentá-lo na seara parlamentar, ou de poder realizar uma ponderação dos interesses em jogo. Assim, se o parlamentar, sem qualquer razão ou fundamento, insulta gravemente minorias étnicas ou culturais, defende doutrinas nazistas ou xenófobas, prega o genocídio ou incita a prática de terrorismo, é provável e admissível que as circunstâncias e o peso dos princípios envolvidos levem o julgador a afastar a regra constitucional insculpida no art. 53 da CF. (DIAS, 2012)

Essa possibilidade não está isenta de críticas, especialmente pelo campo que a alternativa abre em reduzir o debate parlamentar e produzir um espaço de insegurança jurídica (SILVA, p. 51). Por isso, aponta-se a possibilidade do sistema de contraofensas ou revide, (VERONESE: 2006; p. 151-152), um expediente que pode ser útil para ataques e defesas entre indivíduos, porém não se apresenta como alternativa eficaz quando o insulto é dirigido contra um grupo. Ao analisar o sistema estadunidense, solução similar ao revide é apresentada por Meyer-Plufg, baseando-se no remédio de "mais liberdade de expressão":

\footnotetext{
A expressão odiosa ou agressiva em um discurso deve ser respondida, contestada por outro discurso (mais liberdade de expressão) que neutralize ou a refute. Só se deve restringir a liberdade de expressão, no caso do discurso do ódio, se o conteúdo demonstrar um dano claro, atual e iminente. Há que, necessariamente, se distinguir entre fatos, ações e opiniões. Todavia, frise-se que a Primeira Emenda da Constituição americana não protege a violência. Apenas condutas devem ser proibidas, não as expressões (MEYERPLUFG:2009; p. 144).
}

O sistema de contraofensas ou revide - ou, na dicção norte-americana, mais "liberdade de expressão" - ou mesmo a possibilidade de expressão das ideias contrárias, num contexto de combate de ideias, são remédios tímidos, mas indispensáveis para minimizar os efeitos do discurso do ódio. Outra possibilidade é considerar o discurso do ódio como ofensa ao próprio decoro parlamentar, a ser analisado sempre interna corporis, como limitador da fala, na perspectiva das possíveis restrições à liberdade de expressão. $\mathrm{O}$ decoro parlamentar protege a honra coletiva do parlamento (TEIXEIRA: 1996; p. 112).

Esses mecanismos inerentes ao próprio debate parlamentar e de vigilância da sociedade podem ser usados em favor do combate ao discurso de ódio, mas provavelmente devem ser somados a atos concretos, ou seja, acompanhados de atitudes (em substância), especialmente quando há abuso das prerrogativas constitucionais asseguradas aos membros do Poder Legislativo (CONSTITUIÇÃO FEDERAL, art. 55, $\S 1^{\circ}$ ), estando entre elas as imunidades parlamentares (BIM: 2006; p. 77). Por derradeiro, não se pode deixar de refletir sobre o julgamento do STF no Inquérito $\mathrm{n}^{\circ} 3.590$, em que o tema "discurso do ódio" foi abordado. Nesse caso, mesmo acolhendo os argumentos da defesa e considerando atípica a conduta do parlamentar Marco Feliciano, a Suprema Corte brasileira evidenciou que a proteção da imunidade parlamentar ocorre quando existe um elo entre a atividade do parlamentar e a sua fala.

Em contrapartida, o parlamentar argumentou que estaria defendendo os interesses de seus representados. Um dilema para análise casuística será analisar o contexto da fala odiosa e a sua 
relação com a defesa dos interesses dos eleitores, assim como diferenciar opiniões privadas da efetiva atividade parlamentar, para que a inviolabilidade não se transforme num escudo protetor de abusos, cujo mais frequente desvirtuamento de sua finalidade é a utilização para ofender e injuriar sem justificativa (VERONESE: 2006; p. 148).

\section{CONCLUSÃO}

O discurso de ódio contra minorias sociais em estado de vulnerabilidade (negros, quilombolas, gays, lésbicas, transgêneros, pobres) evidencia a existência de instituições (família, Estado, sociedade, igrejas) que, fundadas nas máximas generalizantes propostas pela modernidade, padronizam condutas e impõe modos de viver, como mecanismo de segregação, preconceito, marginalidade e exclusão de todos aqueles sujeitos que destoam do modus pasteurizado e ideologizado de se construir como pessoa ou grupo. O exercício do direito fundamental de liberdade de expressão no Estado Democrático de Direito, no contexto da imunidade parlamentar, é considerado legítimo quando se verifica a não violação da dignidade humana, direitos fundamentais, direitos humanos e princípio da não-discriminação.

Por isso, os limites jurídico-constitucionais e democráticos hábeis a compreender a imunidade parlamentar exigem que o deputado ou senador, no exercício de suas funções, tenha liberdade de expressão, mas não enxergando e compreendendo essa liberdade como algo irrestrito e ilimitado. Tal afirmação se justifica porque o debate parlamentar tem como objetivo fortalecer as instituições democráticas e, por isso, permitir que tais parlamentares reproduzam discurso de ódio em suas falas contraria a sistemática proposta pelo texto constitucional, além de endossar a natural condição de desigualdade estrutural vivenciada pelas minorias sociais vulneráveis.

Blindar o parlamentar dentro da máxima trazida pela imunidade constitucional constitui um meio de tornar invisível o debate do direito à diferença, tão relevante na sociedade contemporânea marcada pela diversidade e pluralismo. Ademais, institucionalizar o discurso de ódio na esfera parlamentar é o mesmo que legitimar a ofensa aos direitos humanos e os direitos fundamentais, especialmente a dignidade humana, direito à igualdade, princípio da não-discriminação e liberdade de expressão.

A complexidade do fenômeno do discurso do ódio localiza-se na possibilidade de existir uma variedade de formas de manifestações e de tipos diferentes de ódio, que indicam a dificuldade da construção de um padrão conceitual para o problema. Nessa trilha, foram analisados os conceitos fornecidos pela dogmática jurídica e os modelos de discurso de ódio. Além disso, apontaram-se alguns traços característicos que podem auxiliar na compreensão e na sistematização do fenômeno. Pode-se formular um conceito de discurso de ódio que englobe todos os critérios proibidos de discriminação - o discurso do ódio consiste na manifestação de ideias intolerantes, preconceituosas e discriminatórias contra indivíduos ou grupos vulneráveis, com a intenção de lhes ofender a dignidade e incitar o ódio em razão dos seguintes critérios: idade, sexo, orientação sexual, identidade e expressão de gênero, idioma, religião, identidade cultural, opinião política ou de outra natureza, origem social, posição socioeconômica, nível educacional, condição de migrante, refugiado, repa- 
triado, apátrida ou deslocado interno, deficiência, característica genética, estado de saúde física ou mental, inclusive infectocontagioso, e condição psíquica incapacitante, ou qualquer outra condição.

Esse discurso do ódio - além de estar presente nas várias esferas da sociedade - pode-se fazer presente também no parlamento, como se pode notar na manifestação feita pelo Twitter, objeto do Inquérito n. ${ }^{\circ}$ 3.590/STF, bem como na palestra ministrada no Clube Hebraico no Rio de Janeiro, responsável por gerar o Inquérito n. ${ }^{\circ}$ 4.694/STF. Nessas manifestações, as palavras utilizadas pelos parlamentares tornam evidentes o discurso discriminatório, com intuito de insultar e de ofender a dignidade de homossexuais e quilombolas, em razão da orientação sexual e origem daqueles que são ofendidos.

Marcar essas manifestações como albergadas no conceito do discurso do ódio é um dos passos importantes para a sua superação e tais discursos lançam um desafio de como enquadrar essas manifestações diante da imunidade parlamentar. No artigo, foi abordada a questão, apresentando-se as seguintes possibilidades: a) aumentar o debate no parlamento sobre as questões objeto do discurso parlamentar, o que seria próprio do sistema de debate parlamentar; b) responder - administrativa, civil e penalmente - pelos atos, (b1) flexibilizando-se o sistema de imunidade parlamentar na via do abuso parlamentar; (b2) adotando-se uma tese mais restritiva do que se entende por propter

officium; e c) responsabilizar o parlamentar por falta de decoro. É preciso dizer que muitas vezes esses discursos feitos por parlamentares podem apresentar uma estratégia de ataque coordenado, com afinidades ideológicas compartilhadas, sob o argumento da proteção moral da família tradicional, provocando ataques constantes à dignidade de grupos não dominantes ou vulneráveis.

A construção de uma sociedade livre, justa e solidária, sem preconceitos de origem, raça, sexo, cor, idade e quaisquer outras formas de discriminação, passa também pelo combate a discursos - seja na esfera parlamentar, seja em outra esfera - que infrinjam esse mandamento constitucional. Os critérios regentes para o discurso parlamentar são o exercício da liberdade de expressão, de modo a não tornar o interlocutor e seus destinatários invisíveis e em posição de desigualdade e exclusão. No momento em que o Poder Judiciário deixa de punir juridicamente parlamentares que comprovadamente proferem discursos odiosos contra minorias sociais, endossa essa estrutura que naturaliza a exclusão e marginalidade desses sujeitos, além de permitir que o parlamento seja utilizado como espaço segregacionista e de reprodução de ideais misóginos, racistas, xenófobos, machistas e homofóbicos, mantendo a invisibilidade desses sujeitos, por considera-los inaptos ao gozo e exercício igual dos direitos civis.

\section{REFERÊNCIAS}

ALEXY, Robert. Tres Escritos Sobre los Derechos Fundamentales y la Teoría de los Principios. Bogotá: Universidad Externado de Colômbia, 2003.

BIM, Eduardo Fortunato. A cassação de mandato por quebra de decoro parlamentar: sindicabilidade jurisdicional e tipicidade. In: Revista de Informação Legislativa, Brasília, Subsecretaria de edições Técnicas do Senado Federal, v. 43, n. 169, p. 65-94, jan./mar. 2006.

BITTAR, Eduardo C. B.. Reconhecimento e direito à diferença: teoria crítica, diversidade e a cultura dos direitos humanos. São Paulo: Rev. da Faculdade de Direito da Universidade de São Paulo. v. 104. Jan/dez 2009. 551-565p. Disponível em: link dando erro verificar. Acesso em: 01 mai. 2019. 
BRASIL. Ato Institucional n. 5, de 13 de dezembro de 1968. Diário Oficial da União, 13 dez., 1968. Disponível em: http://www.planalto.gov.br/ccivil 03/AIT/ait-05-68.htm. Acesso: 12 out. 2018.

BRASIL. O Globo. Disponível em https://oglobo.globo.com/sociedade/assassinatos-de-lgbt-crescem-30-entre-2016-2017-segundo-relatorio-22295785. Acesso em 22 set. 2019.

BRASIL. Constituição (1988). Constituição da República Federativa do Brasil de 1988. Brasília: Senado Federal, Subsecretaria de Edições Técnicas, 1988.

BRASIL. Lei $n$. 7.716, de 5 de janeiro de 1989. Define os crimes resultantes de preconceito de raça ou de cor. Diário Oficial União, 6 jan. 2015. Disponível em: http://www.planalto. gov.br/ccivil 03/leis/17716.htm. Acesso em: 3 mar. 2015.

BRASIL. Superior Tribunal de Justiça. Recurso em mandado de segurança n. 12.388/SP. DJ, 18 dez. 2001. Relator: Ministro Francisco Falcão. Diário da Justiça, 25 mar. 2002.

BRASIL. Supremo Tribunal Federal. Inquérito n. 3.590/DF. Relator: Ministro Marco Aurélio. DJ, 12 ago. 2014. Diário da Justiça Eletrônico, 12 set. 2014.

BRASIL. YouTube. Jair Bolsonaro: palestra no Hebraica Rio de Janeiro. Disponível em: https://www.youtube.com/watch? $\mathrm{v}=\mathrm{LPj} 4 \mathrm{KyLw} 8 \mathrm{Wc}$. Acesso em: 22 set. 2019.

BRUGGER, Winfried. Proibição ou Proteção do Discurso do Ódio: Algumas Observações sobre o Direito Alemão e o Americano. In: Direito Público, Porto Alegre, ano 4, n. 15, p. 117-136, jan./mar. 2007.

CARDOSO, L. Branquitude acrítica e crítica: A supremacia racial e o branco anti-racista. In: Revista Latino Americana de Ciências Sociales, Niñes Y Juventud, Manizales. v. 8, n. 1, p. 607-630, jan.jun. 2010. Disponível em: http://www.scielo.org.co/pdf/rlcs/v8n1/v8n1a28 .pdf. Acesso em: 09 jun. 2019.

DIAS, Roberto Moreira; LAURENTIIS, Lucas Catib de. Imunidades parlamentares e abusos de direitos: uma análise da jurisprudência do Supremo Tribunal Federal. In: Revista de Informação Legislativa, Brasília, v. 49, n. 195, p. 7-24, jul./set. 2012.

DIAZ, Alvaro Paul. La Penalización de la Incitación al odio a la Luz de la Jurisprudencia Comparada. In: Revista Chilena de Derecho, v. 38, n. 2, p. 503-609, 2011.

ESPANHA. Jornal el Pais. Disponível em: https://brasil.elpais.com/brasil/2018/09/11/politica/1536684954_057287.html. Acesso em: 4 de jun. 2019.

FARIAS, Camilo de Lélis Diniz de. A nova ordem constitucional e a tutela do direito à diferença. Revista Direito e Liberdade, Natal, v. 17, n. 1, p. 11-33, jan./abr. 2015. Quadrimestral. Disponível em: http://www. esmarn.tjrn.jus.br/revistas/index.php/revista_dire ito_e liberdade/article/view/718/641. Acesso em: 01 jun. 2019.

GARGARELLA, Roberto. Constitucionalismo y Libertad de Expresión. In: ORDOÑEZ, María Paz Ávila; SANTAMARÍA, Ramiro Ávila; GERMANO, Ramiro Gómez. Libertad de expresión: debates, alcances y nueva agenda. Quito, Ecuador: Organización de las Naciones Unidas para la Educación, la Ciencia y la Cultura, 2011.

HABERMAS, Jürgen. Direito e democracia: entre facticidade e validade. Tradução de Flávio Beno Siebeneicher. v. 2. Rio de Janeiro: Tempo Brasileiro, 2003.

HABERMAS, Jürgen. Mudança estrutural da esfera pública: investigações quanto a uma categoria da sociedade burguesa. Rio de janeiro: Tempo Brasileiro, 2003.

HELLER, Agnes. A condição política pós-moderna. Tradução Marcos Santarrita. Rio de Janeiro: Civilização Brasileira, 1998.

IPEA. Atlas da violência de 2017. CERQUEIRA, Daniel; LIMA, Renato Sergio de; BUENO, Samira; VALENCIA, Luis Iván; HANASHIRO, Olaya; MACHADO, Pedro Henrique G.; LIMA, Adriana dos Santos (Coord.). Disponível em: http://www.ipea.gov.br/portal/images/170602 atlas_da_violencia 2017. pdf. Acesso em: 26 maio 2019. 
Discurso de ódio e os limites jurídico-constitucional-democráticos da imunidade parlamenta...

COSTA, F. V.; PINTO, A. A.

KURAKANA, Jorge. Imunidades parlamentares: São Paulo: Editora Juarez de Oliveira, 2002. 288 p.

MARTINS MARQUES, Amanda Ravena; MUNIZ, Arnaldo Brasil: BRANDÃO, Maureen da Silva. A liberdade de expressão e suas ameaças: reflexões a partir do caso Ellwanger (HC 82.424). [2013]. (Série Monografias do CEJ, v. 16). Disponível em: http://www2.cjf.jus. br/ojs2/index.php/mono/article/view/1810. Acesso em: 6 jun. 2019.

MARTINS, Thiago Penido. Discriminação nas relações contratuais. Belo Horizonte: D’Plácido, 2016.

MEYER-PFLUG, Samantha Ribeiro. Liberdade de expressão e discurso do ódio. São Paulo: Editora Revista dos Tribunais, 2009. 271p.

MISKOLCI, Richard. Pânicos morais e controle social: reflexões sobre o casamento gay. In: Cadernos Pagu, Campinas, n. 28 jan./jun.2007. Disponível em: http://www.scielo.br/scielo.php?script=sci arttext\&pid=S0104-83332007000100006. Acesso em: 8 jun. 2019.

OLIVEIRA, Rodrigo Valin de. As imunidades parlamentares e o poder legislativo. In: Colóquio de pesquisa e pós-graduação, 5. UNIRITTER, Porto Alegre. Disponível em: http://www.uniritter.edu.br/uploads/arquivos/Col\%C3\%B3quio\%20de\%20Pesquisa.pdf. Acesso em: 12 de jul. 2019.

ONU. Declaração Universal dos Direitos Humanos. [S.1.: s.n]. 1948. Disponível em: http s://www.ohchr. org/EN/UDHR/Pages/Language.aspx?LangID=por. Acesso em: 01 mai. 2019.

ORGANIZAÇÃO DOS ESTADOS AMERICANOS - OEA. Convenção americana sobre os direitos humanos: pacto de San José da costa rica: assinada na conferência especializada interamericana sobre direitos humanos. San José, Costa Rica, 7 a 22 de novembro de 1969. Washington: OEA, 1970. Disponível em: https://www.cidh.oas.org/basicos/portugues/c.convencao_americana.htm. Acesso em: 22 set. 2019.

ORGANIZAÇÃO DOS ESTADOS AMERICANOS - OEA. Convenção interamericana contra toda forma de discriminação e intolerância. Guatemala., [6 jun. 2013]. Disponível em: https://www.oas.org/en/sla/ dil/docs/inter_american_treaties_A-68_Convencao_Interamericana_racismo_POR.pdf. Acesso em: 22 set. 2019.

PIOVESAN, Flávia. Ações afirmativas da perspectiva dos direitos humanos. Cadernos de Pesquisa, São Paulo, v. 35, n. 124, p. 43-55, jan./abr. 2005.

PIOVESAN, Flávia. Direitos humanos e justiça internacional: um estudo comparativo dos sistemas regionais, europeu, interamericano e africano. 3. ed. rev. ampl e atual. São Paulo: Saraiva, 2012.

RAMOS, André de Carvalho. O Supremo Tribunal Federal Brasileiro e o Controle de Convencionalidade: Levando a Sério os Tratados de Direitos Humanos. In: Revista da Faculdade de Direito da Universidade de São Paulo, v. 104, [s.n.], p. 241-286, jan./dez. 2009. Disponível em: http:// www.revistas.usp.br/rfdusp/ article/view/67857/70465. Acesso: 12 out. 2018.

RIOS, Roger Raup. Direito da antidiscriminação: discriminação direta, discriminação indireta e ações afirmativas. Porto Alegre: Livraria do Advogado Editora, 2008. 295p.

SANTOS, Rodrigo Hamilton dos; LEIVAS, Paulo Gilberto Cogo; SCHÄFER, Gilberto. Discurso de ódio Da abordagem conceitual ao discurso parlamentar. RIL Brasília a. 52 n. 207 jul./set. 2015. Disponível em: https://www12.senado.leg.br/ril/edicoes/52/207/ril_v52_n207_p143.pdf. Acesso em: 22 set. 2019.

SANTOS, Boaventura de Sousa; NUNES, João Arriscado. Introdução: para ampliar o cânone do reconhecimento, da diferença e da igualdade. In: Reconhecer para Libertar: Os caminhos do cosmopolitanismo multicultural. Rio de Janeiro: Civilização Brasileira, 2003.

SARMENTO, Daniel. A Liberdade de Expressão e o Problema do Hate Speech. In: Revista de Direito do Estado, Rio de Janeiro, ano 1, [s.v.], n. 4, [s.p.], out./dez. 2006.

SCHÄFER, Gilberto. A reparação do dano ao projeto de vida na corte interamericana de direitos humanos. In: Revista de Direitos Fundamentais e Democracia, Curitiba, v. 13, n. 13, p. 179-197, jan.-jun. 2013.

ROMULADO, Edson Carlos; SANTOS, Elaine de Morais. Midiatização e espetacularização: os entornos da campanha político eleitoral de Lula em 2002. In: POSSENTI, Sírio; PASSETTI, Mária Célia (Org.). 
Estudos do texto e do discurso: política e mídia. Maringá: Eudem, 2010. 193p.

ROSENFELD, Michel. Hate Speech in Constitutional Jurisprudence: a Comparative Analysis. In: Public Law Research Paper, n. 41, Cardozo Law School, abr. 2001. Disponível em: http:// papers.ssrn.com/sol3/ papers.cfm?abstract id=265939. Acesso em: 4 out. 2018.

SILVA, Virgílio Afonso da. Direitos fundamentais: conteúdo essencial, restrições e eficácia. São Paulo: Malheiros, 2017a.

SILVA, Rosane Leal da et al. Discurso do ódio em redes sociais: jurisprudência brasileira. In: Rev. direito GV, São Paulo, v. 7, n. 2, p. 445-467, jul.-dez. 2011b.

TEIXEIRA, Carla Costa. Decoro parlamentar: a legitimidade da esfera privada no mundo público?. In: Revista Brasileira de Ciências Sociais, São Paulo, [s.v.], n. 30, p. 110-127, 1996.

TAYLOR, Charles. As fontes do self: a construção da identidade moderna. 4. ed. São Paulo: Edições Loyola, 2013.

VERONESE, Osmar. Inviolabilidade parlamentar: do senador ao vereador. Porto Alegre: Livraria do Advogado, 2006. 171p.

VITAL DA CUNHA, Cristina; LOPES, P. V. L. Religião e política: uma análise da atuação de parlamentares evangélicos sobre direitos das mulheres e LGBTs no Brasil. Rio de Janeiro: Fundação Heinrich Böll Brasil, 2013.

Data de submissão do artigo: Setembro de 2019

Data de aceite do artigo: Março de 2020(*)

\section{(*) NOTA TÉCNICA:}

Esclarecemos que, em razão do ataque de hackers a que foi submetido o conjunto de periódicos da Universidade Federal de Goiás (UFG), ao que se inclui a Revista da Faculdade de Direito da UFG (RFD/UFG), os artigos ordenados entre os números 21-30, referentes ao volume 43, embora tenham sido recebidos e aceitos em datas distintas e anteriores, dado o perecimento de suas referências, foram todos registrados com o expediente de aceite no mês de março de 2020. 